\title{
V30 as a predictor for radiation-induced hypothyroidism: a dosimetric analysis in patients who received radiotherapy to the neck
}

\author{
Zuleyha Akgun ${ }^{1 *}$, Beste M Atasoy² ${ }^{2}$ Zeynep Ozen ${ }^{3}$, Dilek Yavuz ${ }^{4}$, Bahadir Gulluoglu ${ }^{5}$, Meric Sengoz ${ }^{6}$ \\ and Ufuk Abacioglu ${ }^{3}$
}

\begin{abstract}
Introduction: The purpose of this study is to evaluate the possible predictors of thyroid disorders after neck radiotherapy, with a focus on radiation dose-volume factors.

Methods: Thyroid function was measured in 100 patients who had received radiotherapy to the neck, including the thyroid. All radiation-induced thyroid dysfunctions were determined with an endpoint of abnormal thyroid stimulating hormone (TSH), free triiodothyronine (fT3) and thyroxine (fT4) and thyroid peroxidase antibodies and (TPA). The total volume of the thyroid, mean radiation dose to the thyroid (Dmean) and thyroid volume percentage that received radiation doses of 10-50 Gy (V10-V50) were calculated in all patients. The evaluated risk factors for thyroid dysfunction included dose-volume parameters, sex, age, previous surgery, chemotherapy and comorbidity.

Results: There were 52 patients with hypothyroidism and V30 $(p=0.03)$, thyroid volume $(p=0.01)$ and Dmean $(p=0.03)$ appeared to be correlated with hypothyroidism in univariate analysis. However, there was not association found in multivariate analysis for these factors.
\end{abstract}

Conclusions: Thyroid disorders after radiation therapy to the neck still represent a clinically underestimated problem. V30 may be a useful tool for evaluating the risk of hypothyroidism when determining an individual patient's treatment.

Keywords: Dosimetric analysis, Hypothyroidism, Radiotherapy

\section{Background}

The thyroid gland is one the most radiosensitive normal tissues in the human body. It is frequently affected by radiotherapy in head and neck patients, and thyroid dysfunctions are commonly seen following irradiation [1,2]. The incidence of radiation-induced hypothyroidism has been described mostly within the range of $20-30 \%$ and the reports are currently increasing in literature [1-25]. Nonetheless, it still remains an underestimated problem in routine clinical practice [3-5]. Some dosimetric studies exploring radiation-induced thyroid dysfunction have suggested that a thyroid dose of $\geq 30 \mathrm{~Gy}$ is associated with higher risk for hypothyroidism $[1,4,6,7]$.

\footnotetext{
* Correspondence: zuleyhaakgun@gmail.com

'Department of Radiation Oncology, Bezmi Alem Vakif University Medical

School, Adnan Menderes Bulvari, 34093 Istanbul, Fatih, Turkey

Full list of author information is available at the end of the article
}

However, Kim et al. [8] found that the percentage of thyroid volume absorbing $>45$ Gy was observed to be the optimal variable for predicting the development of hypothyroidism, and they suggested a V45 of $50 \%$ as a possible dose-volumetric threshold for radiation-induced hypothyroidism.

In this study, we aimed to evaluate the incidence of thyroid dysfunction following radiotherapy and to explore any potential correlation between thyroid dysfunction and radiation doses in our patients.

\section{Methods}

This study was approved by the Ethical Committee of Marmara University School of Medicine. Between May 2005 and March 2010, 106 patients who had histologically proven non-thyroid malignancies located in the 
head and neck region who were treated in our center were recruited for the analysis. The patients who had existing thyroid dysfunction $(n=6)$ before radiotherapy were excluded from the analysis. There were 30 patients who had surgery to primary tumor and/or neck before radiotherapy. All patients were irradiated at the primary site and the neck and were regularly followed after radiotherapy. The patients and treatment characteristics are summarized in Table 1.

\section{Radiotherapy}

All patients underwent our center's routine procedure for head and neck tumor patients. The patients first underwent a simulation using immobilization with a thermoplastic mask to ensure a reproducible set-up. The patients then underwent a treatment-planning computed tomography $(\mathrm{CT})$ scan with images obtained at 3- to 5-mm slice intervals. The data were transferred to the planning system and 3-D treatment planning using Eclipse (Varian Medical Systems, Palo Alto, CA, USA) was performed for all the patients. Either two opposite equally weighted lateral fields plus one anterior field or anterior-posterior fields or five fields, were used. Treatment was performed with photons (6 MV or $18 \mathrm{MV})$ and/or electrons $(6 \mathrm{MeV}$, $9 \mathrm{MeV}$ to $12 \mathrm{MeV}$ ) using a linear accelerator (Saturne 42, 800 series, General Electric, Buc, France). A total median dose of 60 Gy (range, 36-70 Gy) in 20 to 35 daily fractions of 1.8 or 2 Gy was delivered to the target.

Table 1 Characteristics of the study group

\begin{tabular}{ll}
\hline Characteristics & $\mathbf{n}$ \\
\hline Gender & 32 \\
$\quad$ Female & 68 \\
Male & \\
Age (years) & 50 \\
$\quad$ Median & $17-82$ \\
$\quad$ Range & \\
Tumor site & 38 \\
$\quad$ Nasopharynx & 35 \\
$\quad$ Larynx \& hypopharynx & 15 \\
$\quad$ Oral cavity \& oropharynx & 12 \\
$\quad$ Lymphoma & \\
Chemotherapy & 30 \\
$\quad$ Sequential & \\
$\quad \begin{array}{l}\text { Taxane } 75 \text { mg/m² } 21 \mathrm{~d} \text { and cisplatin } 75 \mathrm{mg} / \mathrm{m}^{2} / 21 \mathrm{~d} \\
\quad \text { Concomitant } \\
\quad \text { Cisplatin } 75 \mathrm{mg} / \mathrm{m}^{2} / 21 \mathrm{~d}\end{array}$ \\
$\begin{array}{l}\text { Previous surgery to primary tumor side and/or neck } \\
\text { Comorbidity (diabetes and/or hypertension) }\end{array}$ \\
\hline
\end{tabular}

\section{Dosimetric analysis}

Treatment plans from all patients were included in this study and the thyroid gland was contoured on each individual CT-slice by the same Radiation Oncologist (ZA). The minimum (Dmin), the maximum (Dmax) and the mean (Dmean) doses the thyroid gland received and the percentage of thyroid volume receiving 10 Gy (V10), 20 Gy (V20), 30 Gy (V30), 40 Gy (V40) and 50 Gy (V50) were calculated using dose volume histograms.

\section{Thyroid function assessments}

The patients were followed for thyroid functions after the completion of radiotherapy with periodic thyroid stimulant hormone (TSH), free thyroxin (fT4), free triiodothyronine (fT3) and thyroid peroxidase antibody (TPA) tests. The first test was obtained at 3 to 6 months after radiotherapy, with the next test at a six months interval thereafter. All tests were measured in the same laboratory using electrochemiluminescence methods (Roche Elecsys 2010 immunoassay analyzer, Roche Diagnostics GmbH, Mannheim, Germany). According to recommendations from the American Thyroid Association, hypothyroidism was defined as a TSH value greater than the upper limit of the normal range. The upper cut off range for TSH that was used was $4 \mathrm{mIU} / \mathrm{L}$ for individuals under 60 years old, $6 \mathrm{mIU} / \mathrm{L}$ for those in the $7^{\text {th }}$ decade and 7 for those in the $8^{\text {th }}$ decade [9].

\section{Statistical analysis}

Statistical analyses were performed using NCSS 2007 \& PASS 2008 Statistical Software (Utah, USA). For statistical analysis, we evaluated the following variables: thyroid absorbed dose, thyroid volume, previous surgery to the primary tumor or to neck, chemotherapy, comorbidity, age, and sex. The relationship between any clinical or treatment parameter and the incidence of thyroid function disorders were analyzed using the appropriate chi-square test or Fisher's exact test for categorical variables and the nonparametric Mann-Whitney $U$ test for continuous variables. The median and range were used to describe all continuous variables. The chi-square test was used to assess the data for correlations among the dose-volume parameters. Continuous variables were dichotomized at median (range) values. A multivariate was used (logistic regression analysis with backward variable selection) and $\beta$ value were calculated for the variables that found significant in univariate analysis. $\mathrm{P}<0.05$ were regarded as significant.

\section{Results}

The median follow-up was 47 months (range, 11 to 80 months). There were 52 patients in whom previous thyroid function tests had been reached. All thyroid function test results were in normal range and none of the 
patients has received a levothyroxine treatment before radiotherapy. During the follow-up, 52 patients developed clinical hypothyroidism and they all were treated with levothyroxine. There were 12 patients who developed thyroiditis, as determined by thyroid ultrasound findings. There were no cases of hypothyroidism (in which the low level of TSH is associated with low levels of fT3 and/or fT4) or hyperthyroidism (in which the high level of TSH is associated with high levels of fT3 and/or fT4) related to pituitary gland dysfunction. The patients' distribution in numbers according to the time that hypothyroidism was detected is shown in Table 2. In summary, the incidence of first diagnosis of hypothyroidism was highest in the first year, especially in the second $6^{\text {th }}$ month period.

The univariate analysis for clinical and dosimetric parameters are shown in Table 3. There were no correlations observed between the incidence of hypothyroidism and the patients' comorbidity, previous surgery, chemotherapy, age and gender. Additionally, there were no significant relationships observed between Dmax or Dmin and hypothyroidism. However, Dmean $(\mathrm{p}=0.03)$, the thyroid volume (31.59 cc vs. $14.25 \mathrm{cc} ; \mathrm{p}=0.01)$ and the analysis of irradiated thyroid volume threshold showed that having whole of thyroid volume irradiated to 30 Gy was a statistically significant predictor for hypothyroidism $(\mathrm{p}=0.03)$. Meanwhile, V10, V20, V40 or V50 were not found to be associated with higher risks of thyroid disorder. In multivariate analysis there was no correlation found for significant parameters of Vmean $(p=0.627$, $\beta=-0.102)$, thyroid volume $(\mathrm{p}=0.06, \beta=-0.188)$ or V30 $(\mathrm{p}=0.07, \beta=0.181)$.

\section{Discussions}

The thresholds for direct thyroid radiation damage are not clear. Investigators have previously reported that the

Table 2 The number of patients developed hypothyroidism according to month intervals

\begin{tabular}{cc}
\hline Interval (months) & Number of patients \\
\hline $2-6$ & 10 \\
$7-12$ & 13 \\
$13-18$ & 2 \\
$19-24$ & 5 \\
$25-30$ & 7 \\
$31-36$ & 6 \\
$37-42$ & 2 \\
$43-48$ & 3 \\
$49-54$ & 1 \\
$55-60$ & 2 \\
$61-66$ & 1 \\
$67-72$ & 1 \\
\hline
\end{tabular}

Table 3 Clinical and dosemiteric factors in patients with and without hypothyroidism

\begin{tabular}{lccc}
\hline & $\begin{array}{c}\text { Normal } \\
(\mathbf{n}=\mathbf{4 8})\end{array}$ & $\begin{array}{c}\text { Hypothyroidism } \\
(\mathbf{n}=\mathbf{5 2})\end{array}$ & $\boldsymbol{P}$ \\
\hline Median Age (year) & 53 & 48 & 0.23 \\
Comorbidity & 9 & 8 & 0.30 \\
Surgery & 16 & 14 & 0.26 \\
Chemotherapy & 32 & 29 & 0.22 \\
Gender & & & 0.12 \\
$\quad$ Female & $46 \%$ & $44 \%$ & \\
$\quad$ Male & $60 \%$ & Median (range) & \\
\hline & $31.59(5.7-99)$ & $14.25(0.6-69.6)$ & 0.01 \\
\hline Thyroid volume & $48.1(0-61.0)$ & $52.1(0.6-59.7)$ & 0.42 \\
Dmin ( $\geq 40.1$ Gy) & $50(19.9-75.3)$ & $47.9(19.4-71.0)$ & 0.49 \\
Dmax ( $\geq 57.6$ Gy) & $44.2(5.7-67.3)$ & $56.2(3.8-66.5)$ & 0.03 \\
Dmean ( $\geq 47.3$ Gy) & $75.0(13-100)$ & $89.1(9-100)$ & 0.06 \\
V10 ( $\geq 100 \%)$ & $67.5(7-100)$ & $82.6(0-100)$ & 0.06 \\
V20 ( $\geq 100 \%)$ & $59.6(0-100)$ & $78.3(0-100)$ & 0.03 \\
V30 ( $\geq 100 \%)$ & $45.9(0-100)$ & $53.6(0-100)$ & 0.36 \\
V40 ( $\geq 94 \%)$ & $54.8(0-100)$ & $45.2(0-100)$ & 0.06 \\
V50 ( $\geq 44 \%)$ & & & \\
\hline
\end{tabular}

incidence of hypothyroidism in various series of patients treated for head and neck cancer varies in a wide range [1-25]. However, most reports state the incidence to be between $20 \%$ and $53 \%$ and the incidence of $52 \%$ found in our study is consistent with these findings. Several dosimetric studies about radiotherapy related thyroid dysfunction and dose volume distribution have been performed in patients receiving irradiation to the thyroid gland $[5,7,8,10,11]$. Yoden et al. [14] reported that the correlation between the percentage of the volume receiving 10 Gy (V10), 20 Gy (V20) and 30 Gy (V30) is a possible predictor of hypothyroidism. Additionally, Bhandare et al. [5] reported a possible dose-volume effect on the increase in the incidence of hypothyroidism, with an increased incidence when $50 \%$ of the thyroid volume received greater radiation doses. Our data showed that V30 was a statistically significant predictor of the development of hypothyroidism $(p=0.03)$. In our study, the thyoid gland was an organ at risk in the treatment field instead of being a target tissue received high doses. There were fewer patients that the gland received high doses like primary tumor ( $\geq 40 \mathrm{~Gy}$ ) and this may be the reason the insignificant correlation for V40 and V50.

Jerezeck et al. [4] showed that smaller thyroid volume was associated with a higher incidence of thyroid toxicity, and Diaz et al. [19] also reported similar findings. Cella et al. [20] developed a multivariate NTCP model for radiation-induced hypothyroidism including V30 and 
thyroid volume. In our analysis, we found a significant correlation between thyroid volume and hypothyroidism $(p=0.01)$. This correlation may be explained by previous surgical procedure. The incidence of hypothyroidism induced by radiotherapy depends on the type of surgical procedure and is high in patients in whom hemithyroidectomy was performed as a part of surgery. Biel et al. [23] showed that the incidence of hypothyroidism in groups of only surgery, radiotherapy and radiotherapy after surgery patients was $47 \%, 23 \%$ and $70 \%$, respectively. These data have been validated by other authors $[6,14,25]$.

The effect of age on hypothyroidism after radiotherapy is not clear. Hancock et al. [1] showed that there is a relationship between hypothyroidism and age. Previous studies by Posner [21] and Hancock [1] showed that female patients had an increased risk for hypothyroidism after radiotherapy. Vrabec et al. [22] observed that female patients had smaller thyroid reserve. However, there are some studies that have shown that there is no correlation between sex and hypothyroidism [18]. We did not find any correlation between sex and thyroid function disorder after radiotherapy in our study. We did not find any correlation between chemotherapy and comorbidity, either.

Radiation-induced hypothyroidism develops after a median interval of 1-1.8 years [21-23]. In our study, hypothyroidism developed 7-24 months after the completion of treatment (Table 2). Therefore, it may be recommended to perform a regular TSH level test from $6^{\text {th }}$ months follow-up after radiotherapy.

In conclusion, the clinical and dosimetric predictors of radiation induced thyroid disorders are not typically distinguished. We found a significant association between the development of hypothyroidism and the V30. Therefore, the V30 may be useful in comparing competing treatment plans to evaluate the risk of hypothyroidism when designing individual patients' treatment.

\section{Competing interest}

The authors declare that they have no competing interest.

\section{Authors' contributions}

ZA involved in the conception and design of the study; acquisition, analysis and interpretation of data; drafting the manuscript and revising it critically for important intellectual content; and giving final approval of the version to be published. BMA involved in the conception and design of the study; acquisition, analysis and interpretation of data; drafting the manuscript and revising it critically for important intellectual content; and giving final approval of the version to be published. $Z O$ involved in the conception and design of the study, the acquisition, analysis and interpretation of data, revising the manuscript critically for important intellectual content and giving final approval of the version to be published. DY involved in the analysis and interpretation of data, revising the manuscript critically for important intellectual content; and giving final approval of the version to be published. BG involved in the analysis and interpretation of data, revising the manuscript critically for important intellectual content giving final approval of the version to be published. MS involved in the analysis and interpretation of data, revising the manuscript critically for important intellectual content and giving final approval of the version to be published.
UA involved in the conception and design of the study, revising the manuscript critically for important intellectual content and giving final approval of the version to be published. All authors read and approved the final manuscript.

\section{Author details}

${ }^{1}$ Department of Radiation Oncology, Bezmi Alem Vakif University Medical School, Adnan Menderes Bulvari, 34093 Istanbul, Fatih, Turkey. ²Department of Radiation Oncology, School of Medicine, Marmara University, Istanbul, Turkey. ${ }^{3}$ Neolife Cancer Center Radiation Oncology Clinic, Istanbul, Turkey. ${ }^{4}$ Department of Internal Medicine Division of Endocrinology, School of Medicine, Marmara University, Istanbul, Turkey. ${ }^{5}$ Department of General Surgery, School of Medicine, Marmara University, Istanbul, Turkey. ${ }^{6}$ Acibadem University Kozyatagi Hospital Radiation Oncology Clinic, Istanbul, Turkey.

Received: 7 January 2014 Accepted: 27 April 2014

Published: 2 May 2014

\section{References}

1. Hancock SL, McDougall IR, Constine LS: Thyroid abnormalities after therapeutic external radiation. Int J Radiat Oncol Biol Phys 1995, 30:1165-1170.

2. Sinard RJ, Tobin EJ, Mazzaferri EL, Hodgson SE, Young DC, Kunz AL, Malhotra PS, Fritz MA, Schuller DE: Hypothyroidism after treatment for nonthyroid head and neck cancer. Arch Otolaryngol Head Neck Surg 2000, 126:652-657.

3. Rønjom MF1, Brink C, Bentzen SM, Hegedüs L, Overgaard J, Johansen J: Hypothyroidism after primary radiotherapy for head and neck squamous cell carcinoma: normal tissue complication probability modeling with latent time correction. Radiother Oncol 2013, 109:317-322.

4. Jereczek-Fossa BA, Alterio D, Jassem J, Gibelli B, Tradati N, Orecchia R: Radiotherapy induced thyroid disorders. Cancer Tr Rew 2004, 30:369-384.

5. Bhandare N, Kennedy L, Malpaya RS, Morris CG, Mendelhall WM: Primary and central hypothyroidism after radiotherapy for head and neck tumors. Int J Radiat Oncol Biol Phys 2007, 68:1131-1139.

6. Weissler MC, Berry BW: Thyroid-stimulating hormone levels after radiotherapy and combined therapy for head and neck cancer. Head Neck 1991, 13:420-423.

7. Kumpulainen EJ, Hirvikoski PP, Viraniemi JA, Johansson RT, Simonen PM, Terävä MT, Asikainen RJ, Nykänen KJ, Kosma V: Hypothyroidism after radiotherapy for laryngeal cancer. Radiother Oncol 2000, 57:97-101.

8. Kim MY, Yu T, Wu HG: Dose-volumetric Parameters for Predicting Hypothyroidism after Radiotherapy for Head and Neck Cancer. Jpn J Clin Oncol 2014, 44:331-337.

9. van der Watt $G$, Haarburger D, Berman P: Euthyroid patient with elevated serum free thyroxine. Clin Chem 2008, 54(7):1239-1241.

10. Bonato CC, Dias HB, Alves Mda S, Duarte LO, Dias TM, Dalenogare MO, Viegas CC, Elnecave RH: In vivo dosimetry of thyroid doses from different irradiated sites in children and adolescents: a cross-sectional study. Radiat Oncol 2014, doi:10.1186/1748-717X-9-40.

11. Cella L, Conson M, Caterino M, De Rosa N, Liuzzi R, Picardi M, Grimaldi F, Solla R, Farella A, Salvatore M, Pacelli R: Thyroid V30 predicts radiationinduced hypothyroidism in patients treated with sequential chemoradiotherapy for Hodgkin's lymphoma. Int J Radiat Oncol Biol Phys 2012, 82(5):1802-1808.

12. Boomsa MJ, Bijl HP, Langendijk JA: Radiation-induced hypothyroidism in head and neck cancer patients: a systematic review. Radiat Oncol 2011, 99(1):1-5.

13. Melmed S: Williams Textbook of Endocrinology (12th ed.), Volume 53. 12th edition. Philadelphia: Elsevier/Saunders.p.355 Children with Hodgkin's disease. Cancer; 1984:878-83.

14. Yoden E, Soejima T, Maruta T, Demizu Y, Nishimura H, Ejima $Y$, Sasaki R, Yamada K, Sugimura K: Hypothyroidism after radiotherapy to the neck. Nihon Igaku Hoshasen Gakkai Zasshi 2004, 64(3):146-150.

15. DeGroot LJ: Radiation and thyroid disease. Bailliere Clin Endocrinol Metabol 1988, 2:777-791.

16. Kim YH, Fayos JV, Sisson JC: Thyroid function following neck irradiation for malignant lymphoma. Radiology 1980, 134:205-208.

17. Dobbs JH: Thyroid damage after treatment of Hodgkin's disease. Clin Oncol 1983, 9:51-56. 
18. Vogelius IR1, Bentzen SM, Maraldo MV, Petersen PM, Specht L: Risk factors for radiation induced hypothyroidism:a literature-based meta-analysis. Cancer 2011, 117(23):5250-5260.

19. Diaz R, Jaboin JJ, Morales-Paliza M, Koehler E, Phillips JG, Stinson S, Gilbert J, Chung CH, Murphy BA, Yarbrough WG, Murphy PB, Shyr Y, Cmelak AJ: Hypothyroidism as a consequence of intensity modulated radiotherapy with concurrent taxane- based chemotherapy for locally advanced head-and-neck cancer. Int J Radiat Oncol Biol Phys 2010, 77(2):468-476.

20. Cella L, Liuzzi R, Conson M, D'Avino V, Salvatore M, Pacelli R: Development of multivariate NTCP models for radiation-induced hypothyroidism: a comparative analysis. Radiat Oncol 2012, 7:224.

21. Posner MR, Ervin TJ, Miller D, Fabian RL, Norris CM Jr, Weichselbaum RR, Rose C: Incidence of hypothyroidism following multimodality treatment for advanced squamous call cancer of the head and neck. Laryngoscope 1984, 94:451-454.

22. Vrabec DP, Heffron TJ: Hypothyroidism following treatment for head and neck cancer. Ann Otol Rhinol Laryngol 1981, 90:449-453.

23. Biel MA, Maisel RH: Indications for performing hemithyroidectomy for tumours requiring total laryngectomy. Arch Otolaryngol Head Neck Surg 1985, 150:435-439.

24. Murthy V, Narang K, Ghosh-Laskar S, Gupta T, Budrukkar A, Agrawal JP. Hypothyroidism after 3-dimensional conformal radiotherapy and intensity modulated radiotherapy for head and neck cancers: Prospective data from two randomized controlled trials. Head Neck 2013, doi:10.1002/hed.23482.

25. Thorp MA, Levitt NS, Mortimore S, Isaacs S: Parathyroid and thyroid function five years after treatment of laryngeal and hypopharyngeal carcinoma. Clin Otolaryngol 1999, 24:104-108.

doi:10.1186/1748-717X-9-104

Cite this article as: Akgun et al.: V30 as a predictor for radiation-induced hypothyroidism: a dosimetric analysis in patients who received radiotherapy to the neck. Radiation Oncology 2014 9:104.

\section{Submit your next manuscript to BioMed Central and take full advantage of:}

- Convenient online submission

- Thorough peer review

- No space constraints or color figure charges

- Immediate publication on acceptance

- Inclusion in PubMed, CAS, Scopus and Google Scholar

- Research which is freely available for redistribution 